\title{
RETRACTED ARTICLE: A catalog of aftershock sequences in Greece (1998-2008) and their spatial and temporal characteristics
}

\author{
Ioannis Baskoutas • Dimitrios Papanastassiou
}

Received: 30 August 2011 / Accepted: 17 May 2012 / Published online: 4 June 2012

(C) Springer Science+Business Media B.V. 2012

The authors have retracted this article [Ioannis Baskoutas and D. Papanastassiou: A catalog of aftershock sequences in Greece (1998-2008) and their spatial and temporal characteristics (DOI 10.1007/ s10950-012-9310-y)]. Even though the article is based on original data, portions of text and its presentation are duplicated without citation, knowledge and permis- sion from another article previously published in Journal of Seismology: "A catalog of aftershock sequences in Greece (1971-1997): Their spatial and temporal characteristics" by George Drakatos and John Latoussakis, Journal of Seismology, Volume 5: 137-145, 2001. The Publisher apologizes for any inconvenience this may cause.

The authors have retracted this article [Ioannis Baskoutas and D. Papanastassiou: A catalog of aftershock sequences in Greece (1998-2008) and their spatial and temporal characteristics (DOI $10.1007 / \mathrm{s} 10950-012-9310-y)]$. Even though the article is based on original data, portions of text and its presentation are duplicated without citation, knowledge and permission from another article previously published in Journal of Seismology: "A catalog of aftershock sequences in Greece (1971-1997): Their spatial and temporal characteristics" by George Drakatos and John Latoussakis, Journal of Seismology, Volume 5: 137145,2001 . The Publisher apologizes for any inconvenience this may cause.

I. Baskoutas $(\bowtie) \cdot$ D. Papanastassiou

National Observatory of Athens, Institute of Geodynamics, P.O. Box 20048, Thission,

GR 11810 Athens, Greece

e-mail: i.basko@noa.gr 